\title{
Lipopolysaccharide-induced cytokine expression pattern in peripheral blood mononuclear cells in childhood obesity
}

\author{
YU WU, BIN YUE and JIA LIU \\ Department of Pediatrics, Cangzhou Central Hospital, Cangzhou, Hebei 061001, P.R. China
}

Received July 17, 2015; Accepted August 1, 2016

DOI: $10.3892 / \mathrm{mmr} .2016 .5866$

\begin{abstract}
Obesity is characterized by the abnormal or excessive fat accumulation that may impair health and extensive increase in body mass index (BMI). Childhood obesity may occur due to disturbances in metabolic regulation, which lead to metabolic syndrome and other diseases. Peripheral blood suspended immune cells are responsible for immune surveillance. The aim of the present study was to map the inflammatory cytokine expression pattern of isolated peripheral blood mononuclear cells (PBMCs) following lipopolysaccharide (LPS) stress in vitro and clinical chemistry parameters in the plasma of subjects. PBMCs were isolated through density gradient ultracentrifugation of the blood from obese infants that would reflect the cytokine response. Isolated PBMCs were cultured in vitro in RPMI-1640 medium and stressed with $1 \mu \mathrm{g}$ LPS in order to investigate the expression pattern of cytokines, such as interleukin (IL)-2, interferon (IFN)- $\gamma$, IFN- $\alpha$, tumor necrosis factor- $\alpha$ and IL- 6 using enzyme-linked immunosorbent assays and reverse transcription-quantitative polymerase chain reaction. Levels of NO, lipid levels, total protein, albumin, marker enzymes aspartate transaminase and alanine transaminase, malondialdehyde (MDA), and reduced glutathione in the plasma were detected. Reduction in the expression of the inflammatory cytokines in PBMCs, reduced protein and globulins, and altered MDA and GSH levels in the plasma were observed. Altered or compromised pro-inflammatory signals from PBMCs in vitro and the clinical chemistry parameters of the plasma suggested that there were compromised immunological responses in obese children compared with matched controls.
\end{abstract}

Correspondence to: $\mathrm{Dr} \mathrm{Yu} \mathrm{Wu}$, Department of Pediatrics, Cangzhou Central Hospital, 201 Xinhua Middle Road, Cangzhou, Hebei 061001, P.R. China

E-mail: yuwu5639@gmail.com

Key words: peripheral blood mononuclear cells, childhood-obesity, interleukin-2, interleukin-6, tumor necrosis factor- $\alpha$, interferon- $\alpha$, interferon- $\gamma$

\section{Introduction}

Obesity $(\mathrm{OB})$ is a risk factor for various metabolic disorders and diseases, such as type II diabetes, hypertension, cardiovascular disease and pulmonary diseases $(1,2)$. Development of metabolic syndrome is highly associated with childhood OB (3). Metabolic syndrome is a collection of risk factors associated with the development of type II diabetes and cardiovascular diseases (4). Dyslipidemia can lead to cardiovascular diseases (5) and studies have documented that obese children tend to become obese adults (6). OB also elevates the risk of viral infections and influenza (7), and defects in host defense in response to mycobacterial, amoeba and fungal infections $(8,9)$. A decreased inflammatory state observed in obese children with decreased cytokine production may lead to various complications associated with $\mathrm{OB}(10)$.

Peripheral blood mononuclear cells (PBMCs) are the sentinels of the innate immune system (11) and include monocytes, natural killer (NK) cells, and T and B lymphocytes (12). Lipopolysaccharide (LPS) derived from gram negative bacteria is a danger signal recognized by PBMCs. Detection of LPS results in transcriptional responses involving the expression of immunological and inflammation-related genes that serve to clear the infection (13). A previous study demonstrated that stimulated PBMCs that are macrophage precursors may contribute to the secretion of cytokines leading to systemic inflammation (14). Peripheral blood-related immunological cells serve as a surveillance body to identify invading microbes (11). Patients with asthma suffer more persistent and severe lower respiratory tract symptoms with decreased gene expression and/or synthesis of interferon (IFN) $-\alpha$, IFN- $\beta$ and IFN- $\lambda$ in epithelial cells and alveolar macrophages $(15,16)$. PBMCs isolated from asthmatic children were reported to secrete less IFN- $\alpha$ following in vitro single stranded viral exposure (17), due to reduced function of toll-like receptor (TLR)-7 (18). Interleukin (IL)-1ß, IL-8 and nuclear factor (NF)- $\mathrm{\kappa B}$ are interrelated genes that are highly associated during expression in LPS intoxication (13). In OB, increased levels of pro-inflammatory cytokines, namely tumor necrosis factor- $\alpha$ (TNF- $\alpha$ ) and IL-6, were observed, which can lead to metabolic syndrome (19) and insulin resistance (20). In addition, higher expression of TLRs and inflammatory cytokines were observed in overweight subjects who were susceptible to metabolic syndrome (21). A positive correlation was observed between levels of IL- 6 and TLR- 4 in the serum and 
monocytes (21). Activation of the TLR signaling cascade in PBMCs may lead to the secretion of a number of cytokines resulting in systemic inflammation (14).

The present study conducted ex vivo stimulation of PBMCs with LPS to demonstrate the expression pattern of inflammatory cytokines in subjects with childhood OB.

\section{Materials and methods}

Study design. Children with OB symptoms who admitted to the Cangzhou Central Hospital between January 2014 and April 2015 were screened for this study. Based on body mass index (BMI) calculated using the formula: Weight $(\mathrm{kg}) /$ height $(\mathrm{m})^{2}$, lipid profile (LP) status, plasma marker enzymes [aspartate transaminase (AST) and alanine transaminase (ALT)] and total white blood cell count in the range $6,000-8,000$ cells $/ \mu 1$, subjects were selected in the age group between 7 and 9 years in the OB and non-obesity (NOB) groups. This study included 23 children (12 boys and 11 girls) in the OB group with an age and gender matched NOB group containing 21 children (11 boys and 10 girls). Their respective BMI was calculated and those exceeding 95th percentile for children and teens of the same age and sex based on World Health Organization were categorized as obese. Informed consent was obtained from all the subjects and their families for participation in the study and ethical approval was obtained from the ethical Committee of Cangzhou Central Hospital, (Cangzhou, China).

Levels of clinical chemistry parameters in subjects. Clinical chemistry parameters total cholesterol (TC), triglycerides (TG), high-density lipoprotein (HDL), total protein (TP) and albumin were analyzed in a fasting (at least $10 \mathrm{~h}$ after dinner) plasma sample of the subjects, prepared from $4 \mathrm{ml}$ of $10 \mathrm{ml}$ venous blood, with heparin used as an anticoagulant. This was calculated using biochemistry autoanalyzer kits from Biosystems S.A. (Barcelona, Spain). according to the manufacturer's protocol using standard solutions provided with the kits. Levels of very low-density lipoprotein (VLDL) were calculated using the formula 0.2xTG. Levels of low-density lipoprotein (LDL) were calculated using Friedewald's formula (22) as follows: LDL=TC-HDL-(0.2xTG).

Assay of reduced glutathione and malondialdehyde (MDA) in subjects. Plasma reduced glutathione levels were analyzed according to the method of Ellman (23) and were expressed as $\mathrm{mg} / \mathrm{dl}$. MDA was determined in plasma by the thiobarbituric acid reaction as described by Ohkawa et al (24).

Assay of marker enzymes in subjects. Marker enzymes for tissue damage, namely AST and ALT, were assayed in the plasma of the subjects using enzymatic method kits (MAK055 and MAK052, Sigma-Aldrich; Merck Millipore, Darmstadt, Germany) according to the manufacturer's protocols. Absorbance was determined using a UV-VIS spectrophotometer.

Isolation and culture of PBMCs. Part of the collected whole blood was used immediately for the isolation of live and active PBMCs. Density gradient ultracentrifugation techniques (20) were used for the isolation of PBMCs after treatment with red blood cell lysis buffer (Sigma-Aldrich; Merck Millipore). Collected samples were centrifuged at room temperature on Ficoll gradient for $30 \mathrm{~min}$ at $300 \mathrm{x} \mathrm{g}$. The separated mononuclear cell layer was twice washed with phosphate-buffered saline (PBS) and PBMCs were cultured in RPMI-1640 medium with $10 \%$ fetal bovine serum (Equitech Bio, Inc., Guangdong, China), $100 \mathrm{U} / \mathrm{ml}$ penicillin and $100 \mu \mathrm{g} / \mathrm{ml}$ streptomycin in a humidified carbon-dioxide incubator with $5 \% \mathrm{CO}_{2}$ at $37^{\circ} \mathrm{C}$.

PBMC stimulation and RNA extraction. Isolated PBMCs were seeded in a 24-well cell culture plate at a concentration of $10^{5}$ cells per ml. After $18 \mathrm{~h}$ of seeding, $1 \mu \mathrm{g} / \mathrm{ml}$ LPS (Sigma-Aldrich; Merck Millipore) was added and cells were incubated for $24 \mathrm{~h}$. After incubation, $50 \%$ of the cells were harvested, and supernatants were collected and stored at $-20^{\circ} \mathrm{C}$ for cytokine analysis. Cytokine levels were determined by enzyme-linked immunosorbent assay (ELISA), according to the manufacturer's instructions. Other cells were treated with TRIzol reagent (Invitrogen, Thermo Fisher Scientific Inc., Waltham, MA, USA) for the preparation and isolation of total RNA for reverse transcription-quantitative polymerase chain reaction (RT-qPCR) amplification of cytokine gene expression. All the experiments were conducted in triplicate and pooled samples were used for RT-qPCR analyses.

Assay of cytokines by ELISA. IL-2 (cat. no. 290063; Eton Bioscience Inc., San Diego, CA, USA), IFN- $\gamma$ (cat. no. 290051; Eton Bioscience Inc.) and TNF- $\alpha$ (cat. no. 430205; BioLegend, Inc., San Diego, CA., USA) levels were assayed using ELISA kits that were purchased from Dakewe Biotech Company Ltd. (Beijing, China). Manufacturer's instructions were followed for all assays and final concentrations were calculated using a standard plot.

Assay of IFN- $\alpha$ and IL- 6 by RT-qPCR. Total RNA was extracted using an RNA extraction kit (Roche Diagnostics, Basel, Switzerland) from isolated PBMCs and the quality was measured spectrometrically and the ratio was found to be between 1.8 and 2.0 at 260/280 $\mathrm{nm}$. After quantification, $200 \mathrm{ng}$ isolated total RNA was used to construct cDNA by reverse transcription (RT) using an RT kit (Roche Diagnostics). DNAse (Roche Diagnostics) was added for the removal of DNA traces. Using synthesized cDNA as a template, relative quantification $(\Delta \Delta \mathrm{Cq})(25)$ of target genes was done in a RT-qPCR using SYBR premix reagents (Applied Biosystems, Thermo Fisher Scientific, Inc.). All the protocols were followed according to the manufacturer's instructions. glyceraldehyde 3-phosphate dehydrogenase (GAPDH) was used as a control gene. Thermocycling conditions were as follows: $94^{\circ} \mathrm{C}$ for 5 sec of denaturation; $55^{\circ} \mathrm{C}$ for $5 \mathrm{sec}$ for annealing and $60^{\circ} \mathrm{C}$ for $30 \mathrm{sec}$ for extension at 40 cycles. Primers for IFN- $\alpha$, IL-6 and GAPDH were purchased from Shanghai Sangon Biotechnology Co., Ltd. (Shanghai, China).

Assay of NO. NO in the biological samples was measured indirectly by measuring the nitrite level in a spectrophotometer at $540 \mathrm{~nm}$ based on the Griess reaction, according to a previous method (26). A standard curve was plotted using various concentrations of potassium nitrite. 


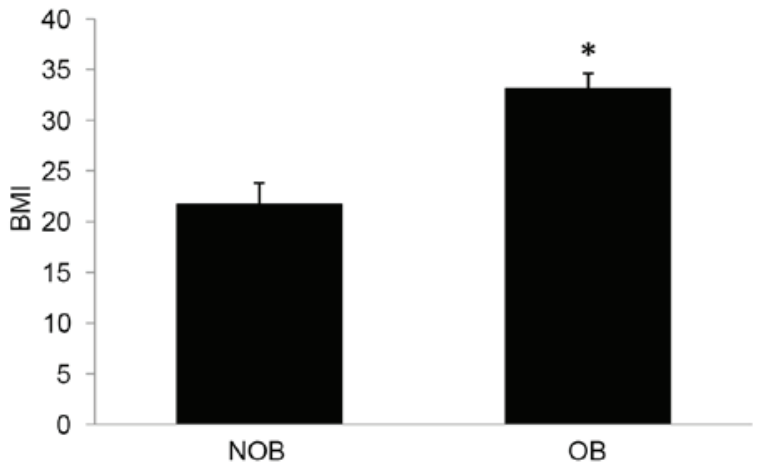

Figure 1. BMI in NOB and OB groups of children. Results are presented as the mean \pm standard deviation. ${ }^{*} \mathrm{P}<0.05$, compared with the NOB group. BMI, body mass index; NOB, non-obesity; $\mathrm{OB}$, obesity.

Statistical analysis. Statistical analysis was conducted using one-way analysis of variance followed by lest-significant difference post-hoc test using SPSS version 14.0 (SPSS, Inc., Chicago, IL, USA). Data are presented as the mean \pm standard deviation. $\mathrm{P}<0.05$ was considered to indicate a statistically significant difference.

\section{Results}

$B M I . \mathrm{BMI}$ is an index to calculate the severity of obesity. Subjects are considered obese if BMI $>30$. A $52.5 \%$ increase in BMI was observed in the OB group (Fig. 1) compared with the matched controls in the present study.

Plasma levels of clinical chemistry parameters. Significantly elevated levels of TC, TG, LDL and VLDL were observed (Table I) and accounted for 33.0, 58.5, 59.8 and 25.7\%, respectively. Conversely, a $12.95 \%$ decrease in the level of HDL was observed in the OB group compared with the NOB group (Table I). Similarly, a $10.15 \%$ decrease in TP and a $9.94 \%$ increase in albumin levels were observed in the OB group compared with the NOB group that showed a significant decrease in globulin level in the OB subjects (Table II). Levels of plasma lipid peroxidation (LPO) and reduced glutathione (GSH) are presented in Table III. Levels of plasma LPO and reduced GSH from LPS exposed cells was quantified via method described previously (27). An $18.97 \%$ increase in LPO and $23.09 \%$ decrease in GSH levels were observed in the OB group compared with the NOB group. No significant difference was identified in the levels of ALT and AST in these groups (Fig. 2).

Protein expression of cytokines. Ex vivo stimulation of PBMCs led to secretion of cytokines into the culture medium. In the OB group, the levels of secretion of the cytokines TNF- $\alpha$, IL-2 and IFN- $\gamma$ were significantly altered compared with that of the NOB group (Figs. 3-5). A 27.15 and $12.28 \%$ decrease in the levels for TNF- $\alpha$ and IFN- $\gamma$, respectively; and an increase of $16.75 \%$ was observed in the IL-2 level. Furthermore, a significant decrease in the NO level (13.51\%) was observed in the OB group compared with the NOB group (Fig. 6).

Cytokine levels detected by RT-qPCR. RT-qPCR was conducted to determine the mRNA expression of IFN- $\alpha$ and
Table I. Levels of lipid profile parameters in NOB and OB groups.

\begin{tabular}{lcc}
\hline Parameter $(\mathrm{mg} / \mathrm{dl})$ & NOB & OB \\
\hline Total cholesterol & $131.4 \pm 15.3$ & $174.8 \pm 13.9^{\mathrm{a}}$ \\
Triglycerides & $80.3 \pm 9.4$ & $127.3 \pm 15.4^{\mathrm{a}}$ \\
VLDL & $15.9 \pm 1.9$ & $25.4 \pm 3.1^{\mathrm{a}}$ \\
LDL & $82.6 \pm 7.4$ & $103.8 \pm 10.6^{\mathrm{a}}$ \\
HDL & $52.5 \pm 4.3$ & $45.7 \pm 4.1^{\mathrm{a}}$ \\
\hline
\end{tabular}

Results are presented as the mean \pm standard deviation. ${ }^{\mathrm{a}} \mathrm{P} \leq 0.05$, compared with NOB. NOB, non-obesity; OB, obesity; VLDL, very-low density lipoprotein; LDL, low density lipoprotein; HDL, high density lipoprotein.

Table II. Levels of total protein, albumin in NOB and OB groups of children.

\begin{tabular}{lcc}
\hline Parameter $(\mathrm{g} / \mathrm{dl})$ & NOB & OB \\
\hline Total protein & $7.98 \pm 0.64$ & $7.17 \pm 0.52^{\mathrm{a}}$ \\
Albumin & $3.62 \pm 0.26$ & $3.98 \pm 0.22^{\mathrm{a}}$
\end{tabular}

Results are presented as the mean \pm standard deviation. ${ }^{\mathrm{a}} \mathrm{P} \leq 0.05$, compared with the NOB group. NOB, non-obesity; OB, obesity.

Table III. Levels of plasma LPO and glutathione in NOB and OB groups of children.

\begin{tabular}{lcc}
\hline Parameter & NOB & OB \\
\hline LPO (nM TBARS/l) & $33.2 \pm 2.7$ & $39.5 \pm 3.4^{\mathrm{a}}$ \\
GSH (mg/dl) & $45.9 \pm 6.4$ & $35.3 \pm 2.8^{\mathrm{a}}$ \\
\hline
\end{tabular}

Results are presented as the mean \pm standard deviation. ${ }^{\mathrm{P}} \mathrm{P} \leq 0.05$, compared with the NOB group. NOB, non-obesity; OB, obesity; TBARS, thiobarbituric acid reactive substances; LPO, lipid peroxidation; GSH, glutathione.

IL-6 (Fig. 7A-C) in NOB and OB groups. A 72 and 64\% decrease in the expression levels of IFN- $\alpha$ and IL- 6 was observed in the OB group compared with the NOB group.

\section{Discussion}

Oxidative stress was shown to induce the expression of pro-inflammatory cytokines, such as TNF- $\alpha$ (27). In host tissues, overproduction of superoxide radicals is associated with diseases, such as cancer and chronic degenerative diseases (28). Conversely, production of reactive oxygen species (ROS) in a minimal levels could lead to the activation of physiological modulations than inducing toxic effects (29). In the present study, a compromise in the reducing capacity of the plasma of the subjects, evidenced by decreased glutathione levels and elevated MDA levels, 


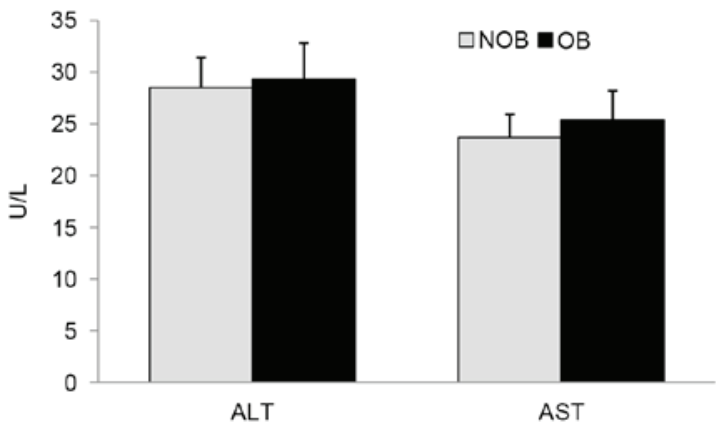

Figure 2. Activities of plasma marker enzymes in NOB and OB groups. Results are presented as the mean \pm standard deviation. NOB, non-obesity; $\mathrm{OB}$, obesity; ALT, alanine transaminase; AST, aspartate transaminase.

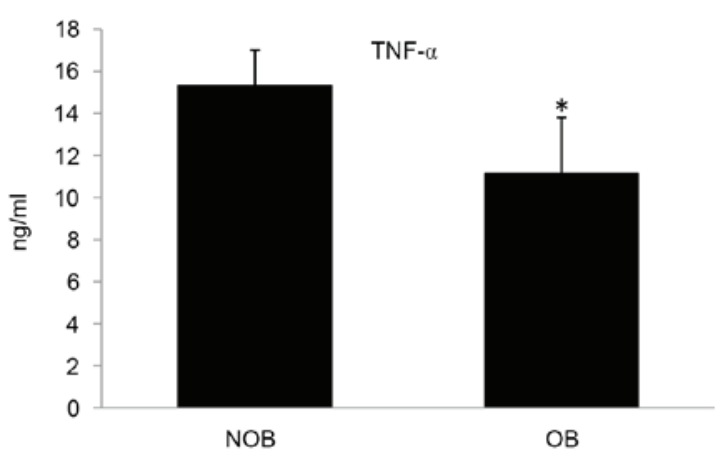

Figure 3. Levels of TNF- $\alpha$ in NOB and OB groups. Results are presented as the mean \pm standard deviation. ${ }^{*} \mathrm{P} \leq 0.05$, compared with the NOB group. TNF- $\alpha$, tumor necrosis factor- $\alpha$; NOB, non-obesity; OB, obesity.

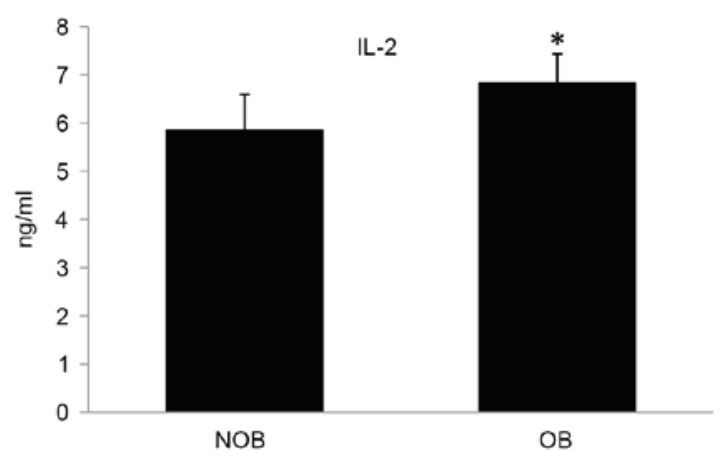

Figure 4. Levels of IL-2 in NOB and OB groups of children. Results are presented as the mean \pm standard deviation. Statistical significance: ${ }^{*} \mathrm{P} \leq 0.05$, compared with the NOB group. NOB, non-obesity; OB, obesity; IL-2, interleukin-2.

depicts the reduced ability of obese subjects to combat infections.

LPS is a potent stimulant that elicits an innate immune response (30). LPS-induced immunological responses mimic the generalized immune response during sepsis (31). The LPS-induced immune response during sepsis profoundly reduces the synthesis of muscle protein in adult animals (32). Septicemia or acute bacterial intoxication may downregulate gene expression involved in protein synthesis (33). A decreased level of total protein in the obese children may underlie the increased risk of infection, and infection may result in an even greater decrease in muscle. Furthermore, increased albumin

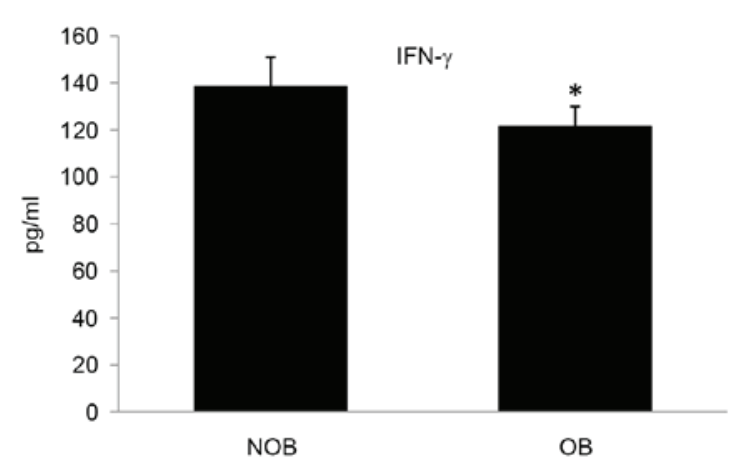

Figure 5. Levels of IFN- $\gamma$ in NOB and OB groups. Results are presented as the mean \pm standard deviation. " $\mathrm{P} \leq 0.05$, compared with the NOB group. IFN- $\gamma$, interferon- $\gamma$; NOB, non-obesity; OB, obesity.

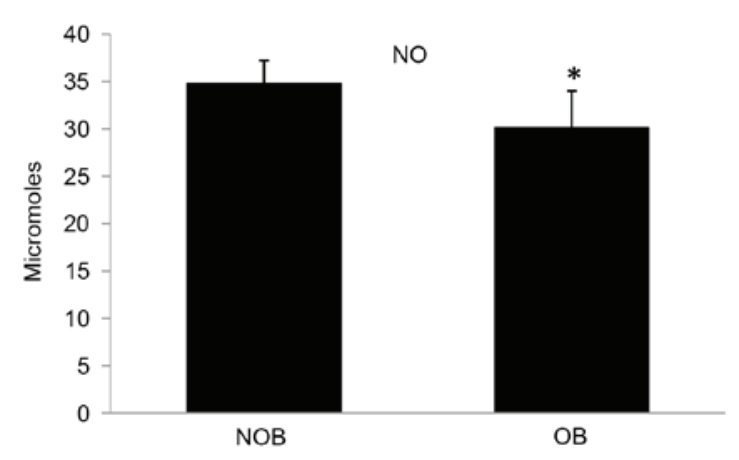

Figure 6. Levels of NO in NOB and OB groups. Results are presented as the mean \pm standard deviation. "P $\leq 0.05$, compared with the NOB group. NO, nitric oxide; NOB, non-obesity; $\mathrm{OB}$, obesity.

in the plasma may be interpreted as a decrease in globulins that are directly involved in immune responses. Due to the decrease in globulins, such as immunoglobulins, the defense activities of children with $\mathrm{OB}$ could be compromised.

An altered lipid profile with increased total cholesterol level was observed in the OB group. Increased cholesterol and decreased HDL-cholesterol (HDL-C) levels could possibly decrease the level of serum $\mathrm{Zn}$ (34). TGs in the serum are positively correlated with the levels of TNF- $\alpha$ in monocytes (21). In a previous study, an abnormally low level of $\mathrm{Zn}$ was observed in the subjects of non-survivors of pediatric septic shock (35) and an extensive downregulation of genes with $\mathrm{Zn}$-related genes (13). In addition, downregulation of $\sim 23 \mathrm{Zn}$-related genes were found in THP-1 cells subjected to LPS stress (13), which mimics bacterial infection. Moreover, decreased serum $\mathrm{Se}$ and $\mathrm{Fe}$, and increased serum $\mathrm{Cu}$ were observed in obese children (34). From these studies, it is evident that pediatric OB may modulate $\mathrm{Zn}$-related annotation bearing genes and possibly favor the chances of infection compared with that in matched controls.

Neonatal pigs and human infants are similar in physiology and metabolism (36). Neonatal pigs exhibit a unique response against acute inflammation when compared with adults (37). Inflammatory responses can be mediated by the secretion of pro-inflammatory cytokines during acute inflammation (38). Administration of LPS or bacterial peptides or related molecules could upregulate the gene annotations and its networks associated with inflammation 
A

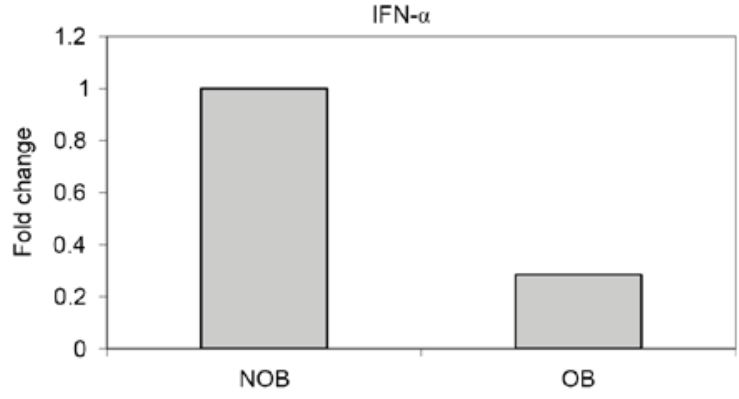

B

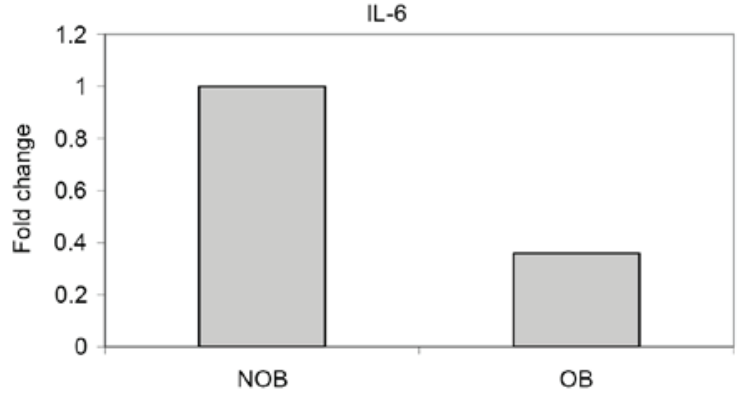

C
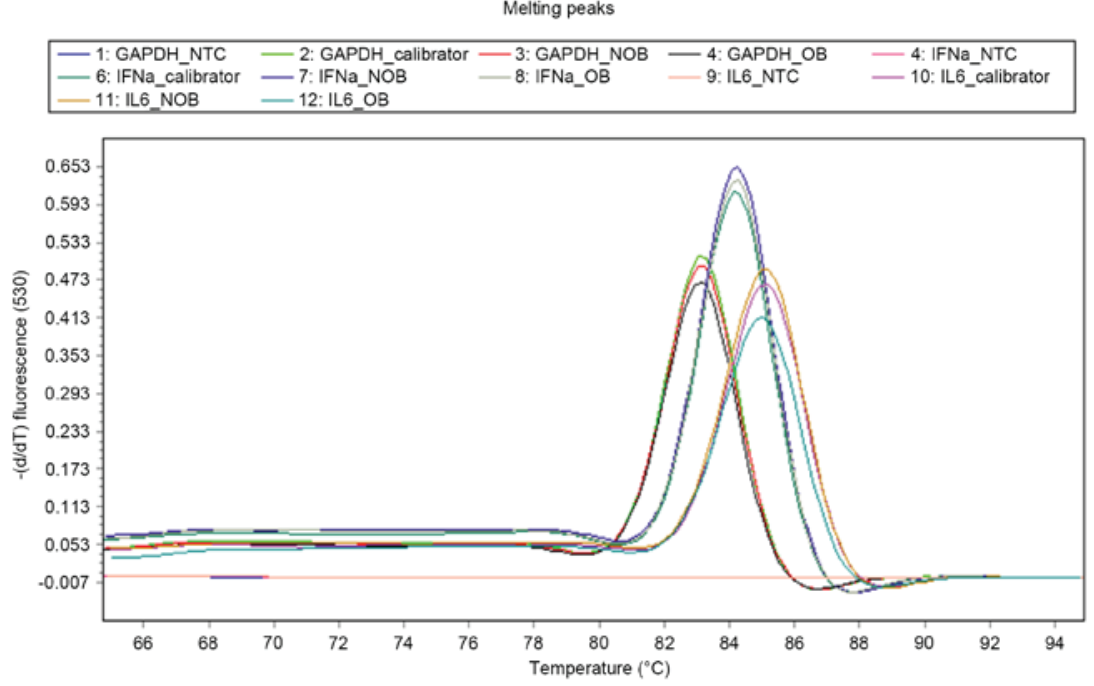

Figure 7. Expression pattern of IFN- $\alpha$ and IL-6 in isolated peripheral blood mononuclear cells induced with LPS in a real time quantitative PCR. (A) Relative expression of IFN- $\alpha$ gene in NOB and OB group, with GAPDH as reference gene. (B) Relative expression of IL-6 gene in NOB and OB group, with GAPDH as reference gene. (C) Melting curves for the control and reference genes. IFN- $\alpha$ and IL-6 LPS, lipopolysaccharide.

and chemokine-related biology (13) and is an important inducer of cytokine secretion (39). Cytokines are important in the immune response (38). In young populations, monocytes are the source of circulating cytokines, such as TNF- $\alpha$, that are elevated in obese subjects compared with controls and contribute to co-morbidities (21). TGs in the serum have been positively correlated with the levels of TNF- $\alpha$ in monocytes (21). The binding of LPS to its receptor complex resulted in the activation and nuclear translocation of interferon regulatory factor-3 and NF- $\kappa \mathrm{B}$, eventually leading to the expression of TNF- $\alpha$ (40). In the present study, subjects in the NOB group secreted higher levels of TNF- $\alpha$ compared with subjects in the OB group in ex vivo experiments. This suggests compromised sensitivity and signaling of inflammatory responses in the OB group.
Upregulation of IL-12 and TNF- $\alpha$ can result in bone-marrow dendritic cell (BMDC) proliferation, initiation of a $\mathrm{CD} 4^{+} \mathrm{T}$ cell response and stability of a $\mathrm{CD} 4^{+} \mathrm{T}$ cell response and a regulation in secretory peptides between DCs and $\mathrm{CD} 4^{+} \mathrm{T}$ cells. This in turn increases the secretion of IL-12 or TNF- $\alpha$ by BMDCs and IFN- $\gamma$ by $\mathrm{CD} 4^{+} \mathrm{T}$ cells leading to immune responses (41).

IFN- $\alpha$ is a soluble cytokine known for its antiviral and immunotherapeutic properties by regulating a diverse set of cytokines (42) and linking innate cell-mediated responses to the adaptive immune response (43). LPS is a natural ligand for the stimulated secretion of IFN- $\alpha$. The immunomodulatory effect of IFN- $\alpha$ against viral infection has been documented in a previous study (41). Interferons are important in directing antiviral effects and regulating innate and adaptive autoimmune 
systems (44). Alone or in combination with other cytokines, IFN- $\alpha$ can regulate BMDCs through direct or indirect pathways. It can also trigger other cells, such as macrophages and NK cells to secrete more cytokines, including IFN- $\alpha$, forming a positive feedback loop (41). IFN- $\alpha$ is an important inducer of the A3 protein family, cellular DNA cytidine deaminases that function as inhibitors of viral replication (45). IFN- $\gamma$ is produced by NK cells and at later stages by differentiated T cells (46). In the present study, decreased expression levels of IFN- $\alpha$ in the OB group compared with the NOB group demonstrated the compromised efficiency to combat viral infections in obese patients.

IL-2 is a pleiotropic cytokine that acts on T-cells (47), B-cells (48) and NK cells (49). IL-2 is an important cytokine that promotes IFN- $\gamma$ production (50) and affects Th-1, Th-2, T-reg and Th-17 cell differentiation to control responsiveness to a range of cytokines after antigen exposure (51). A significant increase in IL-2 was identified in the OB group compared with the NOB group, with the NOB group that confirmed the role of IL-2 in modulating the related cytokines.

$\mathrm{NO}$ is an important physiological messenger molecule of immunological cells (52). NO mediates malarial tolerance in endemic populations demonstrated by increased $\mathrm{NO}$ production in children with asymptomatic-malaria compared with children with severe malaria (53). Exogenous NO supplementation downregulates the production of TNF- $\alpha$ by polymorphonuclear leukocytes (PMNs) from patients with type II diabetes following LPS stimulation and modulation of PMNs response to infection may be dependent upon NO bioavailability (54). IFN- $\gamma$ could also modulate $\mathrm{NO}$ production in certain tumors and decreased production of nitrite could direct the cells to be more prone to apoptosis (55). IFN- $\gamma$ is a highly potent inducer of NO in older patients (56). As more evidence has been published in previous studies $(55,56)$, it could be concluded that IFN- $\gamma$ could induce NO production in the population. In the present study, a decreased level of NO production could be partially due to the significantly decreased IFN- $\gamma$ level in the OB group, which could be correlated from a decreased response of PBMCs in LPS stimulation (Fig. 5). These results support that obesity in children could influence the immunological responses during infection that could lead to life threatening fatal effects.

In conclusion, the present study has indicated the clear linkage between status of immune system with obesity and proper action plan is vital to prevent any mishaps in near future.

\section{References}

1. Gidding SS, Nehgme R, Heise C, Muscar C, Linton A and Hassink S: Severe obesity associated with cardiovascular deconditioning, high prevalence of cardiovascular risk factors, diabetes mellitus/hyperinsulinemia, and respiratory compromise. J Pediatr 144: 766-769, 2004.

2. Sideleva O, Black K and Dixon AE: Effects of obesity and weight loss on airway physiology and inflammation in asthma. Pulm Pharmacol Ther 26: 455-458, 2013.

3. Morrison JA, Friedman LA, Wang P and Glueck CJ: Metabolic syndrome in childhood predicts adult metabolic syndrome and type 2 diabetes mellitus 25 to 30 years later. J Pediatr 152: 201-206, 2008.

4. Hanson RL, Imperatore G, Bennett PH and Knowler WC: Components of the 'metabolic syndrome' and incidence of type 2 diabetes. Diabetes 51: 3120-3127, 2002.
5. Castelli WP, Garrison MS, Wilson PW, Abbott RD, Kalousdian S and Kannel WB: Incidence of coronary heart diseases and lipoprotein cholesterol levels: the Framingham study. JAMA 256: 2835-2838, 1986

6. Wong ND, Bassin S and Deitrick R: Relationship of blood lipids to anthropometric measures and family medical history in an ethnically diverse school aged population. Ethn Dis 1: 351-363, 1991.

7. Akiyama N, Segawa T, Ida H, Mezawa H, Noya M, Tamez S and Urashima M: Bimodal effects of obesity ratio on disease duration of respiratory syncytial virus infection in children. Allergol Int 60: 305-308, 2011.

8. Wieland CW, Florquin S, Chan ED, Leemans JC, Weijer S, Verbon A, Fantuzzi $G$ and van der Poll T: Pulmonary Mycobacterium tuberculosis infection in leptin-deficient ob/ob mice. Int Immunol 17: 1399-1408, 2005.

9. Guo X, Roberts MR, Becker SM, Podd B, Zhang Y, Chua SC Jr, Myers MG Jr, Duggal P, Houpt ER and Petri WA Jr: Leptin signaling in intestinal epithelium mediates resistance to enteric infection by Entamoeba histolytica. Mucosal Immunol 4: 294-303, 2011.

10. Schwarzenberg SJ and Sinaiko AR: Obesity and inflammation in children. Paediatr Respir Rev 7: 239-246, 2006.

11. Miller SI, Ernst RK and Bader MW: LPS, TLR4 and infectious disease diversity. Nat Rev Microbiol 3: 36-46, 2005.

12. Luna AL, Acosta-Saavedra LC, Lopez-Carrillo L, Conde P, Vera E, De Vizcaya-Ruiz A, Bastida M, Cebrian ME and Calderon-Aranda ES: Arsenic alters monocyte superoxide anion and nitric oxide production in environmentally exposed children. Toxicol Appl Pharmacol 245: 244-251, 2010.

13. Wong HR, Odoms K and Sakthivel B: Divergence of canonical danger signals: The genome-level expression patterns of human mononuclear cells subjected to heat shock or lipopolysaccharide. BMC Immunol 9: 24, 2008.

14. Dasu MR, Devaraj S, Park S and Jialal I: Increased toll-like receptor (TLR) activation and TLR ligands in recently diagnosed type 2 diabetic subjects. Diabetes Care 33: 861-868, 2010.

15. Contoli M, Message SD, Laza-Stanca V, Edwards MR, Wark PA, Bartlett NW, Kebadze T, Mallia P, Stanciu LA, Parker HL, et al: Role of deficient type III interferon-lambda production in asthma exacerbations. Nat Med 12: 1023-1026, 2006.

16. Wark PA, Johnston SL, Bucchieri F, Powell R, Puddicombe S, Laza-Stanca V, Holgate ST and Davies DE: Asthmatic bronchial epithelial cells have a deficient innate immune response to infection with rhinovirus. J Exp Med 201: 937-947, 2005.

17. Gehlhar K, Bilitewski C, Reinitz-Rademacher K, Rohde G and Bufe A: Impaired virus-induced interferon-alpha 2 release in adult asthmatic patients. Clin Exp Allergy 36: 331-337, 2006.

18. Roponen M, Yerkovich ST, Hollams E, Sly PD, Holt PG and Upham JW: Toll-like receptor 7 function is reduced in adolescents with asthma. Eur Respir J 35: 64-71, 2010.

19. Hivert MF, Sullivan LM, Fox CS, Nathan DM, D'Agostino RB Sr, Wilson PW and Meigs JB: Associations of adiponectin, resistin, and tumor necrosis factor-alpha with insulin resistance. J Clin Endocrinol Metab 93: 3165-3172, 2008.

20. Hotamisligil GS: Inflammation and metabolic disorders. Nature 444: 860-867, 2006.

21. Hardy OT, Kim A, Ciccarelli C, Hayman LL and Wiecha J: Increased toll-like receptor (TLR) mRNA expression in monocytes is a feature of metabolic syndrome in adolescents. Pediatr Obes 8: e19-e23, 2013.

22. Warnick GR, Knopp RH, Fitzpatrick V and Branson L: Estimating low-density lipoprotein cholesterol by the Friedewald equation is adequate for classifying patients on the basis of nationally recommended cutpoints. Clin Chem 36: 15-19, 1990.

23. Ellman GL: Tissue sulfhydryl groups. Arch Biochem Biophys 82: 70-77, 1959.

24. Ohkawa H, Ohishi N and Yagi K: Assay for lipid peroxides in animal tissues by thiobarbituric acid reaction. Ana Biochem 95: 351-358, 1979.

25. Livak KJ and Schmittgen TD: Analysis of relative gene expression data using real-time quantitative PCR and the 2(-Delta Delta C(T)) method. Methods 25: 402-408, 2001.

26. Hilbert T, Poth J, Frede S, Klaschik S, Hoeft A, Baumgarten G and Knuefermann P: Anti-atherogenic effects of statins: Impact on angiopoietin-2 release from endothelial cells. Biochem Pharmacol 86: 1452-1460, 2013.

27. Sakurai T, Kaise T and Matsubara C: Inorganic and methylated arsenic compounds induce cell death in murine macrophages via different mechanisms. Chem Res Toxicol 11: 273-283, 1998.

28. Goetz ME and Luch A: Reactive species: A cell damaging rout assisting to chemical carcinogens. Cancer Lett 266: 73-83, 2008. 
29. Valko M, Leibfritz D, Moncol J, Cronin MT, Mazur M and Telser J: Free radicals and antioxidants in normal physiological functions and human disease. Int J Biochem Cell Biol 39: 44-84, 2007.

30. Webel DM, Finck BN, Baker DH and Johnson RW: Time course of increased plasma cytokines, cortisol and urea nitrogen in pigs following intraperitoneal injection of lipopolysaccharide. J Anim Sci 75: 1514-1520, 1997

31. Agwunobi AO, Reid C, Maycock P, Little RA and Carlson GL: Insulin resistance and substrate utilization in human endotoxemia. J Clin Endocrinol Metab 85: 3770-3778, 2000.

32. Lang CH, Frost RA, Jefferson LS, Kimball SR and Vary TC: Endotoxin-induced decrease in muscle protein synthesis is associated with changes in eIF2B, eIF4E, and IGF-I. Am J Physiol Endocrinol Metab 278: E1133-E1143, 2000.

33. Orellana RA, O'Connor PM, Bush JA, Suryawan A, Thivierge MC, Nguyen HV, Fiorotto ML and Davis TA: Modulation of muscle protein synthesis by insulin is maintained during neonatal endotoxemia. Am J Physiol Endocrinol Metab 291: E159-E166, 2006.

34. Azab SF, Saleh SH, Elsaeed WF, Elshafie MA, Sherief LM and Esh AM: Serum trace elements in obese Egyptian children: A case-control study. Ital J Pediatr 40: 20, 2014.

35. Wong HR, Shanley TP, Sakthivel B, Cvijanovich N, Lin R, Allen GL, Thomas NJ, Doctor A, Kalyanaraman M, Tofil NM, et al: Genome-level expression profiles in pediatric septic shock indicate a role for altered zinc homeostasis in poor outcome. Physiol Genomics 30: 146-155, 2007.

36. Orellana RA, Kimball SR, Nguyen HV, Bush JA, Suryawan A Thivierge MC, Jefferson LS and Davis TA: Regulation of muscle protein synthesis in neonatal pigs during prolonged endotoxemia. Pediatr Res 55: 442-449, 2004.

37. Yelich MR and Witek-Janusek L: Glucose, lactate, insulin, and somatostatin responses to endotoxin in developing rats. Shock 2 : 438-444, 1994

38. Borish L and Rosenwasser L: Update on cytokines. J Allergy Clin Immunol 97: 719-730; quiz 734, 1996.

39. Okeoma CM, Low A, Bailis W, Fan HY, Peterlin BM and Ross SR: Induction of APOBEC3 in vivo causes increased restriction of retrovirus infection. J Virol 83: 3486-3495, 2009.

40. May MJ and Ghosh S: Signal transduction through NF-kappa B. Immunol Today 19: 80-88, 1998.

41. Song Q, Meng Y, Wang Y, Li M, Zhang J, Xin S, Wang L and Shan F: Maturation inside and outside bone marrow dendritic cells (BMDCs) modulated by interferon- $\alpha$ (IFN- $\alpha$ ). Int Immunopharmacol 17: 843-849, 2013.

42. Perales C, Beach NM, Gallego I, Soria ME, Quer J, Esteban JI, Rice C, Domingo E and Sheldon J: Response of hepatitis C virus to long-term passage in the presence of alpha interferon: Multiple mutations and a common phenotype. J Virol 87: 7593-7607, 2013.
43. LammD, Brausi M,O'Donnell MA and Witjes JA:Interferon-alpha in the treatment paradigm for non-muscle-invasive bladder cancer. Urol Oncol 32: 35.e21-35.e30, 2014.

44. Perry AK, Chen G, Zheng D, Tang H and Cheng G: The host type I interferon response to viral and bacterial infections. Cell Res 15: 407-422, 2005.

45. Zhang W, Zhang X, Tian C, Wang T, Sarkis PT, Fang Y, Zheng S, $\mathrm{Yu} \mathrm{XF}$ and $\mathrm{Xu}$ R: Cytidine deaminase APOBEC3B interacts with heterogeneous nuclear ribonucleoprotein $\mathrm{K}$ and suppresses hepatitis B virus expression. Cell Microbiol 10: 112-121, 2008.

46. Schoenborn JR and Wilson CB: Regulation of interferon-gamma during innate and adaptive immune responses. Adv Immunol 96: 41-101, 2007.

47. Rochman Y, Spolski R and Leonard WJ: New insights into the regulation of T cells by gamma (c) family cytokines. Nat Rev Immunol 9: 480-490, 2009.

48. Blackman MA, Tigges MA, Minie ME and Koshland ME: A model system for peptide hormone action in differentiation: Interleukin 2 induces a B lymphoma to transcribe the $\mathrm{J}$ chain gene. Cell 47: 609-617, 1986.

49. Henney CS, Kuribayashi K, Kern DE and Gillis S: Interleukin-2 augments natural killer cell activity. Nature 291: 335-338, 1981.

50. Reem GH and Yeh NH: Interleukin 2 regulates expression of its receptor and synthesis of gamma interferon by human T lymphocytes. Science 225: 429-430, 1984.

51. Liao W, Lin JX and Leonard WJ: IL-2 family cytokines: New insights into the complex roles of IL-2 as a broad regulator of t helper cell differentiation. Current Opinion Immunology 23: 598-604, 2011

52. Bredt DS and Snyder SH: Nitric oxide: A physiologic messenger molecule. Annu Rev Biochem 63: 175-195, 1994.

53. Anstey NM, Weinberg JB, Hassanali MY, Mwaikambo ED, Manyenga D, Misukonis MA, Arnelle DR, Hollis D, McDonald MI and Granger DL: Nitric oxide in Tanzanian children with malaria: Inverse relationship between malaria severity and nitric oxide production/nitric oxide synthase type 2 expression. J Exp Med 184: 557-567, 1996.

54. Elahi MM and Matata BM: Nitric oxide-dependent regulation of cytokines release in type-II diabetes mellitus. ISRN Inflamm 2013: 531026, 2013.

55. Ghosh S, Bandyopadhyay S, Mukherjee K, Mallick A, Pal S, Mandal C, Bhattacharya DK and Mandal C: O-acetylation of sialic acids is required for the survival of lymphoblasts in childhood acute lymphoblastic leukemia (ALL). Glycoconj J 24: 17-24, 2007

56. Faulkner H, Turner J, Kamgno J, Pion SD, Boussinesq M and Bradley JE: Age- and infection intensity-dependent cytokine and antibody production in human trichuriasis: The importance of IgE. J Infect Dis 185: 665-672, 2002. 